\title{
A ética do documentário: o Rosto e os outros ${ }^{1}$
}

\author{
César Guimarães*, Cristiane da Silveira Lima**
}

\begin{abstract}
Resumo
Este artigo analisa alguns componentes da dimensão ética implicada nos procedimentos expressivos do documentário e critica o privilégio concedido à relação sujeito-objeto como traço definidor da noção de "representação do outro". Em contraposição a essa perspectiva, o artigo reivindica que a abordagem da questão ética no documentário deve ser buscada no plano da escritura filmica, tomada como uma mediação - de natureza intersubjetiva - entre a aparição singular do Outro individualizado e a alteridade indistinta dos vários outros da vida social.
\end{abstract}

Palavras-chave: documentário - ética - mediação

\begin{abstract}
This article analyses some components of the ethical dimension entailed in documentary expressive procedures and also criticizes the privileged status given to the subject-object relationship as an ultimate trace of the notion of the "representation of the other". Contrasting such perspective, the article claims that the approach to the ethical question in documentary genre must be pursued in the plane of filmic writing, considered as a mediation - of intersubjective nature - between the singular apparition of the individualized Other and the indistinct alterity of the several others of social life.
\end{abstract}

Keywords: documentary - ethics - mediation

\footnotetext{
* Doutor em Literatura Comparada pela FALE-UFMG, professor do Programa de Pós-Graduação em Comunicação Social

da UFMG e pesquisador junto ao CNPq.

** Mestranda pelo Programa de Pós-Graduação em Comunicação Social

da UFMG e bolsista da FAPEMIG (Fundação de Apoio à Pesquisa do Estado de Minas Gerais).

'Este texto foi extraida da participação na mesa-redonda dedicada aos "Aspectos filosóficos da ética do documentário", por ocasiāo da VII Conferência Internacional do Documentário, no âmbito da programação paralela do XII Festival "É tudo verdade" (Sảo Paulo, Itaú Cultural, 28 a 30 de março de 2007).
} 


\begin{abstract}
Estou decididamente separado de outrem, se outrem deve ser considerado como aquilo que é essencialmente outro que não eu, mas também, é por essa separação que a relação com o outro se impõe a mim como me ultrapassando infinitamente: uma relação que me remete ao que me ultrapassa e me escapa na medida em que, nesta relação, eu sou e permaneço separado.
\end{abstract}

Maurice Blanchot

Quando discutimos as questões éticas próprias do documentário - e que concernem tanto à relação entre quem filma e quem é filmado quanto à relação com o espectador - evoca-se comumente as possibilidades e os impasses da representação do Outro. Conhecemos a tipologia que Bill Nichols retirou da tríade formada pelo cineasta, tema (atores sociais) e público, com suas duas formas clássicas de interação: "Eu falo deles para você" e "Eu falo - ou nós falamos - de nós para você". 2

Parece-nos, entretanto, que a perspectiva do autor, embasada em uma concepção excessivamente racionalista do documentário (a ponto de subordinar quase que inteiramente a dinâmica da pulsão escópica à epistefilia), fornece somente uma discussão inicial dos componentes éticos específicos do documentário. Com efeito, Nichols se preocupa, sobretudo, com as consequiências que a intervenção do cineasta adquire junto aos atores sociais, seja no momento da filmagem, seja no domínio da recepção, quando eles têm suas vidas expostas aos espectadores, o que pode torná-las vulneráveis a uma série de apropriações e até mesmo de ataques dos quais o filme não tem como protegê-los.

Se tal tipologia parece-nos insuficiente é porque, ao centrar-se na relação sujeito-objeto, ela não apreende verdadeiramente o trabalho da representação. Antes mesmo de ser produzida pelo filme - em suas várias instâncias, modulada pelo arranjo particular de seus recursos expressivos - a representação antecede a filmagem e prossegue mesmo depois do filme terminado, quando este se dirige ao espectador. Disseminada na vida social, a representação - mais do que um repertório 
de enunciados no qual se encarnam valores e visões de mundo - é uma forma viva da mediação, um terceiro simbolizante que se interpõe entre o um e o outro. Mise en scène quer dizer precisamente isso: relação a um outro sob a mediação de um terceiro. Assim é que a escritura do filme se depara, de saida, com as representações já existentes, que se acercam não apenas do tema e do sujeito filmado, mas também impregnam os próprios papéis e valores assumidos pelos sujeitos que se encontram interligados pela mise en scène: realizador, sujeito filmado e espectador. Ainda que pudéssemos esboçar um tratado dos deveres que devemos cumprir ao assumir nossa responsabilidade para com aqueles que filmamos, encarregado de regular minimamente o exercício especifico do filme documentário, restará sempre algo de indecidivel, para além de todo contrato, algo não de todo regulável e que permeia essa relação que se estabelece entre nós e os outros, mediados pela escritura específica inventada pelo filme.

No limite, é esta escritura, ora mais, ora menos porosa ao encontro irreproduzivel entre a câmara e o corpo filmado (com seus atributos inumeráveis), quem deve responder pelas questões éticas que demandamos ao cinema documentário. Ao passar pela grade da escritura (operação que implica artifício, perda e sacrifício), os sistemas de representação (responsáveis pelo assujeitamento dos indivíduos à sociedade), podem ser de tal modo trabalhados pelo filme que os espectadores alcancem uma visada crítica das representações que os vinculam ao seu mundo, tal como anota Comolli: "necessidade de passar pelo outro. A representação (o espelho, o ator, a fábula, a narrativa, o espetáculo, a imagem) é o terceiro a partir do qual se constitui minha relação com o outro, sendo ao mesmo tempo parte de mim e diferente de mim". 3

Se o documentário pode sustentar um gesto ético é unicamente no sentido que sua escritura não deve se fazer imediatamente: ao invés de avançar, de partir decididamente para a representação, ela deve permanecer atenta, à espera do Outro, sabendo que, quando ele chegar, será preciso dispor de meios para confrontar e des-naturalizar a representação que o envolve e o sufoca, que faz de seu Rosto uma máscara que o torna indiferente, indistinto, dissolvendo-o em meio aos milhares de Outros indiferenciados que povoam o espaço social.

\section{Os campos éticos do documentário}


Para compreender em que medida essa perspectiva contribui para a discussão atual em torno da dimensão ética do documentário, é preciso indicar historicamente os principais modos com que os filmes conceberam os lugares dos sujeitos filmados e também do espectador (configurando, assim, diferentes posturas éticas).

Fernão Pessoa Ramos (2005) identifica três campos éticos do documentário do século $\mathrm{XX}$, valorizados positivamente nos diferentes períodos históricos e vinculados aos procedimentos estilísticos adotados pelos diversos filmes. Um primeiro momento é guiado por uma ética da missão educativa. Essa tradição do fazer do documental baseavase em uma lógica de valorização das tradições em vias de desaparecimento, frequentemente sob um viés cientificista, culturalista e/ou nacionalista. Ramos situa os clássicos de Flaherty e Grierson neste campo e, no caso brasileiro, Humberto Mauro, cuja produção esteve desde o início vinculada ao Instituto Nacional de Cinema Educativo (Ince). Neste primeiro momento do documentário, a percepção do "outro" é determinada por um olhar altruísta: o discurso educativo enuncia suas verdades para o povo que, por sua vez, deve ser capaz de 148 tirar proveito daquele que educa. A justificativa ética deste tipo de filme está limitada ao conteúdo veiculado e à postura missionária dos seus realizadores.

Nos final dos anos 1950, este modelo educativo chega ao seu esgotamento e dá lugar ao que Ramos chama de uma ética do recuo. Com o desenvolvimento de equipamentos mais leves e que permitiam a gravação do som em sincronia com a imagem, o cinema documentário passa por uma profunda transformação estilística. A postura que passa a guiar os realizadores - agora vinculados ao projeto do cinema direto - baseia-se no recuo do sujeito enunciador e na crítica à idéia de um sujeito do saber. Não se tratava simplesmente de negar todo saber, mas sim de defender um saber que se constituísse no exercício da liberdade do espectador: os cineastas se colocavam no lugar de observadores afastados, adotando o princípio de intervir pouco (ou nada) na realidade filmada. De acordo com Ramos, essa nova postura trazia para a cena temas caros à ética do imediato pós-guerra, influenciada por valores existencialistas sartrianos, tais como liberdade, responsabilidade e ambigüidade. Assim, os cineastas acreditavam que recuar seu ponto de vista permitiria a produção de representações mais ambíguas, de modo a oferecer ao espectador um mundo como "paralelepípedo" (metáfora 
de Bazin), para que este pudesse exercer "sua liberdade/responsabilidade de construir o próprio saber sobre o mundo, em uma postura de sabor existencialista". ${ }^{4}$

Este campo ético, no entanto, logo dá lugar a uma ética participativo-reflexiva. Em meados da década de 60, Leacock, Wiseman, Drew e outros realizadores do cinema direto já buscavam se atualizar e incorporavam características do novo campo que se estabelecia. O sujeito que filma passa a assumir deliberadamente o seu lugar de enunciador, imprimindo suas marcas no filme, enfatizando a necessidade de um corpo-a-corpo com a circunstância do mundo em que o filme é feito (circunstância à qual Ramos chamará de situação de tomada). Trata-se, portanto, de uma lógica oposta à do recuo e da não intervenção, marcada pela concepção desconstrutivista da representação e de reconhecimento da não transparência da imagem. Assim, procedimentos auto-reflexivos são usados com recorrência, tais como evidenciar a presença dos equipamentos (como, por exemplo, uma câmera que filma uma câmera que filma) e do diretor durante as filmagens. Em vez da câmera observadora, os diálogos e entrevistas são largamente utilizados e, com cada vez mais freqüência, o próprio realizador se torna personagem central do filme, adotando uma postura performática. Desse modo, o campo participativo-reflexivo aposta na intervenção dos realizadores na realidade filmada e na construção da reflexividade como saída ética. Essa forma de abordagem tem seu principal marco no chamado cinéma verité, cuja principal referência é, inegavelmente, Jean Rouch.

Se este campo ético é o que vigora até os dias de hoje, no entanto, não existem modelos a serem seguidos ${ }^{5}$. Os filmes lidam à sua maneira com a realidade filmada, através dos recursos expressivos dos quais dispõem - recursos estes que dependem tanto daquilo que é obtido no momento da tomada (entre os que filmam e os que são filmados), quanto no processo de montagem. Em outras palavras: o modo como os filmes encaram o desafio de ir ao encontro do outro é bastante diversificado, e as dificuldades desta tarefa aumentam sobremaneira quando se trata de filmar o outro de classe, pertencente a um grupo social à margem da sociedade e, conseqüentemente, à margem da esfera de visibilidade. 


\section{O aparecer de Outrem}

Diante da impossibilidade de falar por todo o documentário, e sem ter como abarcar a variedade dos componentes éticos implicados em suas diversas modalidades e em cada uma de suas etapas - da filmagem à montagem -, vamos nos deter em algo que é decisivo para certos filmes: a aparição do Outro não apenas sob o modo de sua representação social - o que torna o filme um representante do sujeito filmado, por interposição - mas antes, o surgimento, simultâneo ao aparecer do sujeito filmado, de um conjunto de possibilidades que faz o desejo baixar sobre o mundo expresso por Outrem. Recorremos aqui àquela noção de Outrem como estrutura, tal como definida por Gilles Deleuze: nem um objeto particular nem um outro sujeito, Outrem é a expressão de um mundo possível:

outrem não é nem um objeto no campo de minha percepção, nem um sujeito que me percebe: é, em primeiro lugar, uma estrutura do campo perceptivo, sem a qual este campo no seu conjunto não funcionaria como o faz. Que essa estrutura seja efetuada por personagens reais, por sujeitos variáveis, eu para vós e vós para mim, não impede que ela preexista como condição de organização em geral aos termos que a atualizam em cada campo perceptivo organizado - o vosso, o meu. Assim, Outrem - a priori como estrutura absoluta, funda a relatividade os outrem como termos efetuando a estrutura em cada campo. Mas qual é essa estrutura? É a do possível ${ }^{6}$.

Tais questões, apresentadas em termos filosóficos, podem soar estranhas ao modo como habitualmente abordamos a representação do Outro no domínio do filme documentário. No entanto, para nós, é aí mesmo que reside o cerne da ética que lhe é própria. Como não apreender o outro somente sob o modo atual com que ele aparece para nós, mas, sobretudo, também dando a ver (e a escutar) as possibilidades e as virtualidades que $o$ atravessam? E mesmo diante da aparição singular do Outro (já desembaraçado da representação que o tornava indistinto e indiferente), como podemos compreender - com os recursos expressivos do filme - que ele não é senão o primeiro indício daquilo que desconhecemos, do que não percebemos, do que não sabemos e 
que, desse modo, vem, inevitavelmente, nos descentrar e nos deslocar? Eis o que significa dizer que Outrem encerra um mundo possivel: cada aparição de um outro qualquer (singular ou genérico) vem efetuar, de modo particular, a estrutura-Outrem (nos termos de Deleuze ${ }^{7}$ ). Indiquemos como o problema ético se manifesta aí.

Zygmunt Bauman ressalta que toda a dificuldade da questão ética reside na passagem da relação assimétrica entre Eu e Tu - cena primordial da moral segundo Lévinas - para as situações nas quais surgem o Terceiro na vida social:

Pode a ética, nascida e criada na estufa do encontro de duas pessoas, suportar a investida do Terceiro participante? $\mathrm{E}$ - mais relevantemente -- pode a capacidade moral que se faz sob a medida da responsabilidade pelo Outro como Rosto ser suficientemente forte e potente, ou suficientemente poderosa, para sustentar uma carga inteiramente diversa da responsabilidade pelo "Outro como tal", o Outro sem um Rosto? ${ }^{8}$

Se na cena primordial da relação intersubjetiva o Outro nos aparece em sua singularidade, enquanto Rosto ("presença que eu não posso dominar com o olhar") no domínio na vida social, mundo da multiplicidade de outros, o Terceiro surge delimitado - representado, justamente - por meio de operações como a escolha, a proporção, o julgamento e a comparação, que o incluem em uma categoria e dissolvem seu Rosto, substituido agora por máscaras e estereótipos. Àquela epifania de outrem (segundo a expressão de Blanchot) veio se impor a alteridade indistinta de todos os outros, dos Muitos que habitam um espaço que não é mais o da proximidade e sim, aquele regulado por normas, leis e tribunais de justiça ${ }^{10}$. O problema que atormenta a ética, portanto, reside em como fazer o caminho de volta, isto é, como reencontrar os traços de singularidade naqueles que aparecem a nós como multiplicidade de outros sem rosto? Como, diante deles, por eles nos responsabilizarmos à maneira da nossa relação com o Outro singular? Como estender o gesto da micro-ética (forjado na relação entre-dois) ao domínio ampliado da justiça social (da macro-ética)?

Como nos lembra Maurice Blanchot, ao comentar Lévinas, o rosto transborda toda representação que podemos fazer dele:

O rosto - isso me parece essencial - é esta experiência que faço, quando diante desta face que se oferece a mim sem resistência, 
eu vejo levantar-se, "do fundo destes olhos sem defesa", a partir desta fraqueza, desta impotência, aquilo que se entrega radicalmente a meu poder e o recusa absolutamente, transformando meu maior poder em im-possibilidade. Diante do rosto, menciona Lévinas, eu não posso mais poder. ${ }^{. l}$

Ora, quando se fala de uma ética do documentário, a principal preocupação reside justamente no fato de que o filme começa por ser um investimento de poder, dono de meios discursivos e imagéticos que assujeitam aquele que é filmado, situado, de início, em uma posição que lhe permite bem menos desenvoltura do que àquele que filma. A preocupação ética consistiria, sob esse ponto de vista, em resguardar as prerrogativas do sujeito filmado, ou então, em estabelecer uma relação dialógica entre o cineasta e o personagem. Reconhecemos aqui, sem dificuldade, o que costumeiramente chamamos de uma conduta ética por parte do realizador.

Do ponto de vista da abordagem filosófica das aporias e dilemas da ética, o documentário não se encontra nem uma posição privilegiada nem em desvantagem. Assim como nós mesmos, em nossas práticas cotidianas, desenvolvidas na relação de proximidade com o Outro singular, e também em nossas relações com os outros sem rosto, mediadas por leis e normas, o documentário, com seu dispositivo próprio de imagens, sons e falas, não pode ignorar o tipo de responsabilidade que ele deve (ou consegue) sustentar. Mais do que simplesmente se precaver, cercando-se de cuidados legais, para que a representação do Outro filmado não venha the conferir efeitos daninhos (como um golpe pelas costas), o documentário, não poderia também, como sugere Blanchot, se estirar até o limite, nessa espera pelo Outro, sem pressa, pacientemente, sem procurar defini-lo? Tal atenção, tal firmeza no esperar, sugere Bauman, "não visa despossuir o outro de sua vontade, de sua distintividade e identidade" 12 : ela se contenta em permanecer à espera, atenta, sem se exaurir, na proximidade... Tal tarefa, tão difícil, não seria também desanimadora? E o documentário, por sua vez, disporia de meios para suportá-la melhor? Não seria pedir demais a ele?

Podemos pensar, inicialmente, que nem todas as modalidades do documentário (passadas ou futuras) estão à altura desta exigência ética. No entanto, isso não constitui motivo nem para reforçarmos a 
consagrada divisão entre os filmes dedicados à representação de questões sociais e aqueles outros voltados para o retrato pessoal, nem para restringir essa exigência somente ao domínio das modalidades participativa e reflexiva do documentário, como se depreende do ponto de vista de alguns autores. Ainda que esta exigência ética - formulada nos termos de Lévinas - não possa ser endereçada, retrospectivamente, à história do documentário como um todo (embora vários filmes do passado a tenham enfrentado), cremos que, do ponto de vista heurístico, ainda que recortemos a dimensão ética do documentário em campos distintos, concebidos como padrões conformados historicamente, essa caracterização do dilema ético é válida não apenas para as chamadas modalidades participativa e reflexiva do documentário (a quem ela parece se destinar "naturalmente"), mas alcança também filmes que se servem de outros recursos expressivos.

Independentemente das diferenças entre as modalidades assumidas pelo documentário ao longo de sua história, duas são as dificuldades principais a serem enfrentadas para dar conta dessa singularização da multiplicidade de outros que anima a vida dos atores sociais, eleitos sujeitos do filme. Em primeiro lugar, a escolha da visão como sentido privilegiado para o conhecimento do Outro: encarregada do poder de desvelar o Outro, crente de que poderia desvelá-lo, a visão acaba reduzindo-o ao Mesmo. Em segundo lugar, a relação entre Eu e Outrem não se enquadra no modelo da subjetividade. Outrem - escreve Blanchot - "não está no mesmo plano que eu":

O homem enquanto outrem, sempre vindo do exterior, sempre em relação a mim sem pais, ele, estranho a toda posse, despossuido e sem domicílio, aquele que é como que "por definição" o proletário - o proletário é sempre o outro -, não entra em diálogo comigo: se eu the falo, eu o invoco, e the falo como àquele que não posso atingir nem reduzir a meu bel-prazer, e se ele me fala, ele me fala através da infinita distância que o separa de mim, e sua palavra me anuncia precisamente este infinito. ${ }^{13}$

Para vencer essas duas dificuldades, o documentário, a partir do arranjo de seus recursos expressivos, confrontados com o aquilo que ele se esforça por representar (e que não será de todo representável) 
poderia realizar pelo menos dois gestos: primeiro, promover a disjunção entre a imagem e a palavra e, ao assumir que falar não é ver, libertar a palavra tanto do visível quanto do invisível; em seguida, abandonar o Eu como medida para o conhecimento do Outro, descentrá-lo radicalmente, conceder ao Outro a prioridade que até então era concedida ao $\mathrm{Eu}$.

Dito isso, como podemos transportar tais questões para o domínio das formas expressivas do documentário? Primeiro, assumindo que não há nenhuma diretriz, nenhum método, nenhuma proteção garantida contra os riscos que se corre (e que vêem primeiramente do real). Podemos cunhar várias fórmulas, nenhuma definitiva. Mas se pudéssemos, escolheríamos esta: ao acolher a mise en scène do outro, o documentário enseja uma estética e uma política da hospitalidade, ele desenvolve a paciência de sua escuta e a atenção do olho inumano da câmara para guardar, neste encontro entre o humano e a máquina, os gestos e a voz do outro, sua resistência em ser enquadrado, narrado, encenado. Nas palavras de Jean-Louis Comolli, o que faz o filme documentário é "abrir o diafragma de uma lente, a sensibilidade de uma emulsão, a duração de uma exposição, o tempo de uma passagem, à presença luminosa do outro"'14. Ao invés de avançar, de se apoderar, deixar-se arrastar pelo e para o espaço do outro. Como o documentário poderia fazê-lo?

Eduardo Coutinho, por exemplo, um dos documentaristas de maior relevância no contexto brasileiro contemporâneo e que leva às últimas conseqüências esta idéia de uma poética do encontro, adota a postura de uma aceitação não resignada do mundo, de uma acolhida da realidade em seu caráter único e irremediável. Essa aceitação, no entanto, não significa ser insensível à dor dos outros, nem tampouco não intervir ou acreditar que a realidade "fala por si". Trata-se, antes, de adotar uma postura ética que recusa a complacência com relação àquilo que se filma, ao mesmo tempo em que recusa um "humanismo piedoso". O que Coutinho busca é "tentar conhecer o que está sendo filmado, sem uma idéia preconcebida sobre aquele universo, nem sobre o que se quer passar para o espectador"15.

Não é tarefa fácil para os realizadores abrir mão dos seus pressupostos sobre a realidade social para empreender o projeto do documentário sob o risco do encontro luminoso com outro. Alguns realizadores agem motivados justamente por uma não aceitação do 
mundo tal como é: querem intervir na realidade, transformá-la, denunciar suas injustiças, debatê-las com um público mais ampliado. $\mathrm{E}$, para isso, eles escolhem o documentário como um potencializador da reflexão. É o caso de filmes como Falcão, meninos do tráfico (MV Bill e Celso Athayde - 2006), cujos idealizadores se inserem em um contexto de militância vinculado ao rap, em um projeto coletivo. No entanto, nesse tipo de filme, os sujeitos filmados aparecem freqüentemente já presos ao tema denunciado, o que acaba sendo um tanto quanto restritivo quando se trata de abrir-se ao inesperado que pode surgir no encontro com o outro.

Uma outra estratégia de abordagem adotada pelos documentaristas para falar do outro de classe estigmatizado tem sido a de compartilhar com ele o processo de feitura dos filmes, permitindothe $o$ acesso aos equipamentos de captação e tratamento de imagens e áudio, sobretudo a câmera (como é o caso dos filmes Jardim Nova Bahia, Aloysio Raulino - 1971 e Prisioneiro da Grade de Ferro (Auto retratos), Paulo Sacramento - 2003), e, ainda, propiciando momentos de discussão coletiva sobre as representações que normalmente são feitas sobre eles (como é o caso de Jardim Angela, Evaldo Mocarzel 2006 e de várias outras produções realizadas nas Oficinas Kinofórum). Este é o caso mais típico do que Nichols chama de "nós falamos de nós para você" e dialoga também com a tradição participativo-reflexiva. Mas se por um lado desses encontros saem imagens com un frescor e expressividade sem igual, por outro, essa abordagem corre o risco de retornar a um excessivo didatismo - tanto por parte daqueles que possuem o domínio sobre o fazer documental e que seriam capazes não só de ensinar a fazer, mas também a ver, quanto por parte das Ongs e outras instituições que recorrem ao audiovisual como instrumento para educar e formar "cidadãos" - e, algumas vezes, de forma ingênua, como se o simples gesto de ceder a câmera - permitindo ao sujeito filmado ser também aquele que filma - tornasse o filme mais "legítimo", mais "verdadeiro", mais "ético", por assim dizer. Seja como for, tratase de uma mais estratégia pautada na valorização da dimensão do encontro entre aquele que filma e aquele que é filmado.

A questão da ética do documentário pode incidir sobre as estratégias e procedimentos adotados intencionalmente pelos seus realizadores durante o momento da filmagem, porém, é preciso indagar, em um segundo momento, sobre o que o filme alcança efetivamente, o 
que ele proporciona para o sujeito espectador. Sem dúvida, as imagens têm um potencial de fazer ver, de fazer pensar, de fazer crer e até mesmo de fazer fazer, isto é, de modificar condutas. Por isso é preciso refletir também sobre o lugar que elas reservam para o espectador. Qual seria, por exemplo, o melhor modo de filmar o intolerável, a injustiça, a crueldade, de modo a não deixar o espectador no lugar de um conforto moral? Vivian Sobchack, ao se perguntar sobre a representação da morte no documentário, afirma que o próprio ato da visão está sujeito ao escrutínio moral ${ }^{16}$. Os filmes fornecem bases para pensarmos não apenas a conduta ética do cinegrafista, mas também a nossa em relação ao mundo visível na tela. São os códigos cinematográficos que inscrevem no filme um espaço ético, isto é, uma representação ou signo visível da relação moral subjetiva e vivida do observador com o observado ${ }^{17}$. Em razão do espectador tomar o mundo do documentário como algo concreto, intersubjetivo, em certa medida contíguo ao seu próprio mundo, ele estabelece um laço existencial e ético entre o espaço ocupado pelo filme e o seu próprio espaço, o que faz com que ele assuma uma atitude responsável perante um mundo compartilhado com outros sujeitos.

Comolli afirma que aquilo que desperta o desejo de ver no espectador é precisamente o fato de que aqueles que filmam "garantem" que os corpos filmados são "verdadeiros". Daí toda a relevância de uma reflexão sobre o modo como estes corpos são figurados, uma vez que afirmar a verdade destes corpos implica necessariamente em uma responsabilidade e um poder (de mostrar, de fazer ver). Para Comolli, "não se filma nem se olha impunemente"18. Por isso, o poder de mostrar deve se fundar na relação que funda a possibilidade do filme.

Para melhor caracterizarmos essa perspectiva acerca da dimensão ética do documentário, levando em consideração o modo como surge a singularidade dos sujeitos filmados, comentaremos brevemente um filme realizado no encontro entre o cineasta e o outro de classe (os jovens moradores da periferia de São Paulo, no Jardim Ângela), propiciado por uma oficina ministrada pelo cineasta naquela comunidade. Se em um primeiro momento o cineasta ocupa um lugar privilegiado, sobretudo por ser aquele que ensina e que propõe as atividades, em um segundo momento vemos que os sujeitos filmados (e que também filmam), ao se imbuírem de desejo de entrar no filme, assumem um novo lugar nessa 
relação mediada pela câmera e pelos recursos expressivos próprios do documentário.

\section{O imaginário e a máscara}

No documentário Jardim Ângela (2006), Evaldo Mocarzel filma as atividades dos participantes de uma Oficina Kinofórum, ministrada por ele na periferia de São Paulo. A oficina busca fornecer um aprendizado básico da linguagem cinematográfica e propiciar aos jovens um exercício prático de realização de vídeos.

Desde o início os participantes da oficina manifestam seu descontentamento diante das representações sociais que a grande mídia faz da periferia, ao lhe impingir o estigma da criminalidade e da pobreza, além de abordar seus problemas superficialmente. Para esses jovens a oficina oferece a possibilidade mostrar um outro ponto de vista acerca da sua realidade cotidiana: seu lado ruim - brutalidade de grande parte das ações policiais, o crescimento da guerra entre traficantes, o alcoolismo - mas também seu lado esperançoso - os projetos sociais, o hip hop, a capoeira. Em outras palavras: ao realizarem os filmes, eles desejam introduzir novos elementos nesse conjunto de representações que trata os sujeitos da periferia como uma massa homogênea, diluindo as nuances da vida social e reduzindo-os ao estereótipo, à multiplicidade de outros sem Rosto, à alteridade indistinta dos Muitos.

Já divididos em grupos, os jovens-realizadores lançam-se à dificil empreitada de filmar a comunidade. Mocarzel, por sua vez, acompanha mais de perto um dos grupos, que realiza um video de ficção sobre o alcoolismo. É ali que o cineasta encontrará aquele que vem surpreendêlo e descentrá-lo: Washington, 18 anos, admirador dos filmes de ação e do personagem Zé Pequeno, do filme Cidade de Deus (Fernando Meirelles, 2002).

O personagem ganha destaque já no primeiro exercício proposto pela oficina, quando os jovens deveriam escolher uma imagem que representasse a sua visão sobre o bairro. A idéia do grupo era, inicialmente, fazer um plano-geral do Jardim Ângela, mostrando o contraste da paisagem; no entanto, quando Washington tira a camisa por causa do calor e exibe acidentalmente suas cicatrizes, é seu corpo que se tornará a imagem eleita pelo grupo. Filmado de costas, 
Washington descreve o dia em que viu sua vida "passar como flash" diante dos olhos, e exibe a marca feita pelo disparo dado por um traficante da região.

Aos poucos, o jovem vai dando pistas de sua relação de proximidade com a violência, inicialmente no lugar da vítima. Além do fato de que esteve à beira da morte, logo descobrimos que seu pai era alcoólatra e que fora assassinado dentro de casa. Porém, no decorrer do filme, Washington vai assumindo aos poucos um outro lugar - desta vez o do "bandido" ou algoz: descobrimos que ele já trabalhou para o tráfico de drogas, participou de seqüestros e assaltos, foi preso. Washington aparece sempre manuseando a arma com destreza, tanto durante a interpretação quanto nos momentos em que prepara o objeto de cena: ele mira com cuidado antes de atirar, lustra o revólver cuidadosamente com um pedaço de pano, gira-o em torno do dedo indicador. Os acontecimentos são narrados por ele com desenvoltura, sem inibição ou constrangimento, como se quisesse mostrar sua esperteza, "contar vantagem" da vida fácil (e ao mesmo tempo arriscadíssima) que o tráfico oferece.

Pronto para encarnar o personagem que ele, imaginariamente, acreditava ser, Washington se engaja em um movimento de sedução que atrai e arrasta o filme inteiro de Mocarzel. Tomado por um misto de surpresa e fascínio, o diretor cede todo espaço para o jovem exibir e performar seu imaginário sobre a violência. De um lado, há o jovem que deseja entrar no filme de Mocarzel, fazer dele o seu filme; do outro, um diretor que aceita, sem reservas, a mise en scène do personagem, dando-lhe autonomia para realizar seu desejo, oferecendolhe os meios objetivos (imagens e sons) para tornar visivel seu imaginário.

Quase sem oferecer resistência, Mocarzel e sua equipe são arrastados para o filme roteirizado e encenado por Washington, que se torna, afinal, o protagonista do documentário. Também no vídeo de ficção realizado pelos jovens, que narra a história do alcoólatra assassinado pelo próprio filho, é Washington quem assume o lugar central: ele é o responsável pela escolha do rap do grupo Facção Central como trilha sonora do vídeo, é o diretor - ensinando aos atores como bater, como morrer - e também o parricida, personagem principal. Os recursos expressivos de ambos os filmes (tanto do video do grupo, 
quanto do documentário de Mocarzel) são organizados em função da intervenção de Washington.

O modo como o jovem dá seus depoimentos para câmera, gesticulando e reproduzindo com a voz os sons das ações descritas (o barulho do sangue jorrando de seu corpo, o coração pulsando apressado durante uma fuga, os gemidos de um homem ao morrer queimado), conjugado ao modo como dirige os colegas no vídeo coletivo ("já começou o filme?", "aqui a sombra vai aparecer", "ia ser legal filmar ele pisando em você, assim") revelam uma consciência plena do poder de sua fala e dos seus gestos. No fim das contas, é ele quem dá as coordenadas do que deve ou não ganhar relevo nos dois filmes (aquele que segue o seu roteiro e o de Mocarzel) - ele sabe bem onde termina um filme e onde começa o outro. No entanto, nós espectadores, aos poucos perdemos a compreensão desse limite, de modo que o personagem parricida (o do video e o do rap) se confunde com Washington. A própria edição do documentário reúne, indistintamente, as imagens captadas pela câmera do grupo e pela do cineasta.

Se por um lado o gesto de Mocarzel é generoso ao acolher uma parcela do mundo do outro, permitindo ao jovem interpretar o que quiser - inclusive, um parricida - por outro lado não há distinção entre a vida efetivamente vivida (antes do filme) e o estereótipo do bandido que Washington encarna. Jardim Angela concede a Washington a oportunidade de oferecer aos outros o modo como, imaginariamente, ele gostaria de ser visto, permitindo-lhe representar o seu personagem com total liberdade. Inclusive, o próprio Mocarzel abre mão do seu lugar de superioridade - pois é ele, afinal, o profissional que ministra a oficina - e dá autonomia aos jovens, assumindo o lugar daquele que observa e escuta com atenção. No entanto, se por um lado isso é o que permite ao menino - que investe seu corpo e sua fala no projeto do documentário - realizar seu desejo, por outro, a imagem eleita por Washington para melhor representá-lo (para dar a ver seu Rosto), coincide com a figura estereotipada do bandido. Assim, a aparição do Rosto singular do garoto é encoberta pela máscara social que Washington veste. Se no início do filme, os jovens reclamavam do modo como as representações sociais da favela acabavam por subsumilos ao estereótipo, reduzindo a periferia aos traços predominantes da violência e da miséria, quando finalmente têm a oportunidade de fazer 
a sua própria imagem, eles são tomados novamente pela representação que criticavam.

Para o cineasta Hartmut Bitomsky, "as pessoas são apenas máscaras, as quais se parecem com elas mesmas. O que fazem no filme são tentativas de alcançar uma fisionomia - poderia se dizer: tentativas de dar ao mundo um rosto"'19. O que fazer, porém, quando a máscara com a qual nos parecemos, aquela que nos dilui na massa indistinta dos outros sem Rosto, é a única alcançada pelo documentário? Parece não haver resposta para a questão. Não existe uma fórmula a ser seguida pelos documentários. No entanto, parece-nos que é na própria relação entre cineastas e sujeitos filmados que deve se estabelecer os parâmetros éticos do filme, isto é, no próprio modo como realizadores e sujeitos filmados, juntos, dão prosseguimento à interação, escolhendo os elementos que darão o tom da narrativa, elegendo o que deve ou não aparecer e ganhar maior ou menor relevo na escritura filmica. Tudo depende, afinal, da maneira com que os sujeitos investem seu desejo no filme e do modo com que o cineasta o acolhe - tanto na situação de tomada, quanto na montagem - por meio dos recursos expressivos dos quais dispõe. Assim, não é possível estabelecer, de saída, o que pode ou não ser feito pelos filmes - cada um deve inventar, à sua maneira, seus próprios meios para dar conta da questão ética entrelaçada à interação entre quem filma e quem é filmado.

\section{Notas}

${ }^{2}$ NICHOLS. Introdução ao documentário, p. 26-46.

${ }^{3}$ COMOLLI. Voir et pouvoir - L'innocence perdue: cinema, télévision, fiction et documentaire, p.213.

${ }^{2}$ RAMOS. A cicatriz da tomada: documentário, ética e imagem intensa, p.177.

${ }^{3}$ Em defesa da posição de recuo do cineasta diante do tema filmado - atitude característica da modalidade observativa - Fernão Ramos critica, em tom pejorativo, a hegemonia atual de uma "cartilha participativo-reflexiva". Cf. RAMOS. A cicatriz da tomada: documentário, ética e imagem intensa, p.168.

${ }^{4}$ DELEUZE. Lógica do sentido, p. 316-317.

${ }^{5}$ Notemos, de passagem, que a formulação de "outrem como estrutura" (tomada de empréstimo a Sartre) guarda afinidades estreitas 
com uma outra criação conceitual de Deleuze: a invenção de um "empirismo transcendental", domínio da experiência pura, feito de virtualidades, acontecimentos e singularidades, desvinculado das noções de sujeito, consciência e individuo.

${ }^{6}$ BAUMAN. O mal-estar da pós-modernidade, p. 63.

${ }^{7}$ BLANCHOT. A conversa infinita, p. 102.

${ }^{8}$ BAUMAN. Ética pós-moderna, p. 131.

'BLANCHOT. A conversa infinita, p. 102.

${ }^{10}$ BAUMAN. Ética pós-moderna, p. 103.

$"$ BLANCHOT. A conversa infinita, p.104-105.

${ }^{12}$ COMOLLI. Voir et pouvoir - L'innocence perdue: cinema, télévision, fiction et documentaire, p.11.

${ }^{13}$ LINS. O documentário de Eduardo Coutinho, p.94.

${ }^{14}$ SOBCHACK. Inscrevendo o espaço ético: dez proposições sobre morte, representação e documentário, pp.127-157.

${ }^{15}$ POOLE apud SOBCHACK. Inscrevendo o espaço ético: dez proposições sobre morte, representação e documentário, p.144.

${ }^{16}$ COMOLLI. Carta de Marselha sobre a auto-mise en scène, p. 130 .

${ }^{17}$ BITOMSKY. O mundo documentário, p.155.

\section{Referências} 1997.

BAUMAN, Zygmunt. Ética pós-moderna. São Paulo: Paulus, Zahar, 1998

O mal-estar da pós-modernidade. Rio de Janeiro:

BITOMSKY, Hartmut. O mundo documentário. In: forumdoc.bh.200I - $5^{\circ}$ Festival do Filme Documentário e Etnográfico - Fórum de Antropologia, Cinema e Vídeo. Belo Horizonte, Filmes de Quintal / FAFICH: 2001.pp.154-164. (Catálogo de festival).

BLANCHOT, Maurice. A conversa infinita. São Paulo: Escuta, 2001.

COMOLLI, Jean-Louis. Carta de Marselha sobre a auto-mise en scène. In: forumdoc.bh.2001 - $5^{\circ}$ Festival do Filme Documentário e Etnográfico - Fórum de Antropologia, Cinema e Vídeo. Belo Horizonte, Filmes de Quintal / FAFICH: 2001.pp.109-116. (Catálogo de festival). 
. Voir et pouvoir - L'innocence perdue: cinema, télévision, fiction et documentaire. Paris: Verdier, 2004.

DELEUZE, Gilles Lógica do sentido. São Paulo: Perspectiva, 1974.

LINS, Consuelo. O documentário de Eduardo Coutinho. Rio de Janeiro: Zahar, 2004.

NICHOLS, Bill. Introdução ao documentário. Campinas: Papirus, 2005.

RAMOS, Fernão Pessoa. A cicatriz da tomada: documentário, ética e imagem intensa. In: . Teoria contemporânea do cinema - volume II. São Paulo: Editora Senac São Paulo, 2005. pp.159-227.

SOBCHACK, Vivian. Inscrevendo o espaço ético: dez proposições sobre morte, representação e documentário. In. RAMOS, Fernão Pessoa. Teoria contemporânea do cinema - volume II. São Paulo: Editora Senac São Paulo, 2005. pp.127-157. 